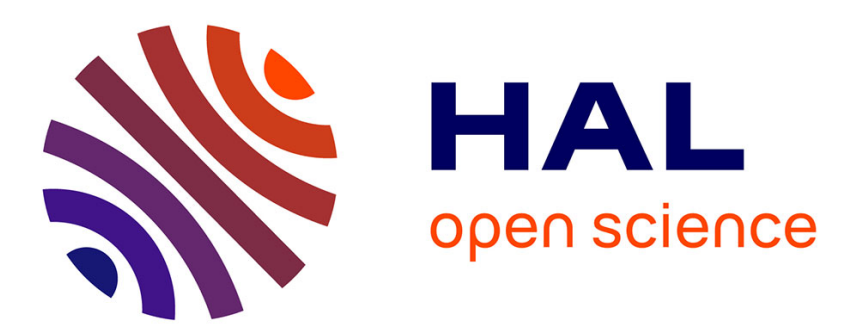

\title{
Probing thermal radiation of single or a small number of plasmonic nano-antennas
}

\author{
Loubnan Abou-Hamdan, Valentina Krachmalnicoff, Riad Haidar, Patrick \\ Bouchon, Yannick de Wilde
}

\section{- To cite this version:}

Loubnan Abou-Hamdan, Valentina Krachmalnicoff, Riad Haidar, Patrick Bouchon, Yannick de Wilde. Probing thermal radiation of single or a small number of plasmonic nano-antennas. Plasmonics: Design, Materials, Fabrication, Characterization, and Applications XIX, Aug 2021, San Diego, United States. pp.64, 10.1117/12.2594091 . hal-03448065

\section{HAL Id: hal-03448065 https://hal.science/hal-03448065}

Submitted on 25 Nov 2021

HAL is a multi-disciplinary open access archive for the deposit and dissemination of scientific research documents, whether they are published or not. The documents may come from teaching and research institutions in France or abroad, or from public or private research centers.
L'archive ouverte pluridisciplinaire HAL, est destinée au dépôt et à la diffusion de documents scientifiques de niveau recherche, publiés ou non, émanant des établissements d'enseignement et de recherche français ou étrangers, des laboratoires publics ou privés. 
Probing thermal radiation of single or a small number of plasmonic nano-

\section{antennas}

\section{Loubnan Abou Hamdan ${ }^{1,2}$, Valentina Krachmalnicoff ${ }^{1}$, Riad Haïdar ${ }^{2}$, Patrick Bouchon ${ }^{2}$, and Yannick De Wilde ${ }^{1}$}

1. ESPCI Paris, Université PSL, CNRS, Institut Langevin, 1 rue Jussieu, F-75005 Paris, France

2. DOTA, ONERA, Université Paris-Saclay, F-91123 Palaiseau, France

Infrared (IR) metamaterials made up of plasmonic resonators have been used in a wide range of applications, such as radiative cooling, photodetection, and solar cell design. In this regard, ensemble systems of metal-insulator-metal (MIM) resonators [1] have been studied extensively. The electromagnetic (EM) modes of the subwavelength antennas making up these structures can be excited both optically and through thermal fluctuations. When dealing with individual or a small number of nano-antennas, highly sensitive techniques, such as thermal radiation scanning tunneling microscopy [2], and infrared spatial modulation spectroscopy (IR-SMS), are required in order to extract the very weak emitted thermal radiation. Using these techniques, it has been possible to characterize both the near- and far-field thermal emission of a single sub- $\lambda$ metalinsulator-metal antenna [3], revealing interesting resonant behavior.

(a)

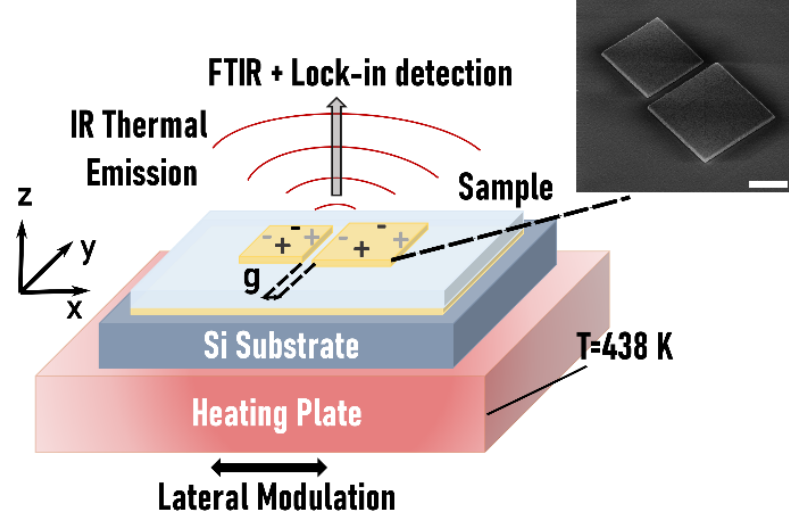

(b)

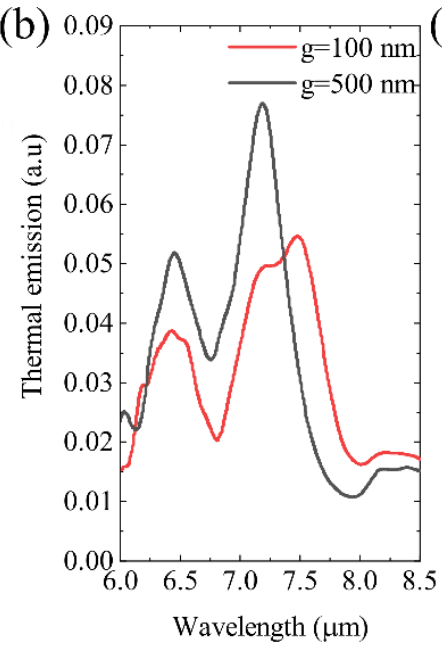

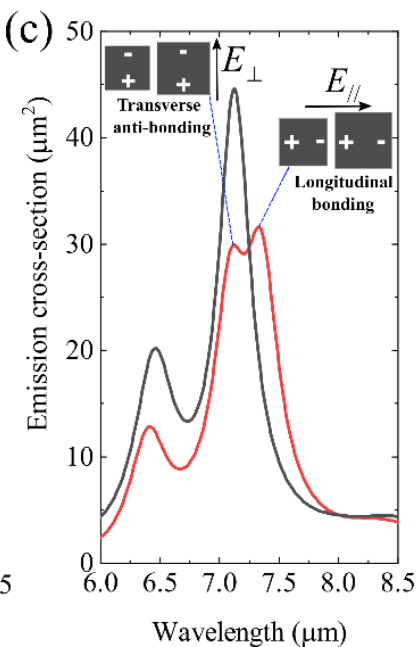

Figure 1. (a) Schematic illustration of the sample geometry and of the IR-SMS technique. The inset shows a scanning electron microscopy image of a MIM antenna pair. (b) Measured thermal emission spectra of the antenna pair for different gap g. (c) FDTD calculations of emission crosssections for normally incident, unpolarized illumination, corresponding to the measurements.

The inset shows a sketch of the dimer geometry showing two of the hybrid modes of the coupled antennas, for electric field polarization parallel and perpendicular to the dimer axis. The positive and negative signs indicate the surface charge distribution [4].

More recently, we have extended this study to a single asymmetric pair of MIM antennas, separated by a nanometric gap $g$ [4]. The geometry of the considered MIM pair is shown in Fig. 1 (a). The far-field spectral response of the thermally excited antenna pair was extracted from the overwhelming background thermal radiation via the IR-SMS technique. As sketched in Fig. 1 (a), the sample is heated to a uniform temperature $(\mathrm{T} \sim 438 \mathrm{~K})$, resulting in a thermal excitation of all 
the EM modes of the antenna pair. A lateral modulation of the sample at a frequency $\Omega$ induces a spatial modulation of the signal emitted by the MIM pair, which is then extracted by lock-in detection after passing through a Fourier transform infrared spectrometer.

As shown in Fig. 1(b) (black curve), for gaps larger than or equal to $\sim 500 \mathrm{~nm}$, the two MIM antennas resonate independently, due to the absence of near-field interaction for such a large gap. However, as the gap $g$ is reduced to $100 \mathrm{~nm}$ (Fig. 1(b), red curve) the two gold patches of the MIM antennas form a dimer pair and a splitting starts to form in the resonance peak between 7 and 8 $\mu \mathrm{m}$, while an overall redshift in the spectrum is also observed. The obtained splitting is a direct result of the simultaneous excitation of the hybrid bonding and anti-bonding modes of the dimer pair [5], shown in the inset of Fig. 1(c). This striking result, which was confirmed by finite difference time domain (FDTD) simulations (Fig. 1(c)) and polarization analysis, shows that various coupled modes of a single nano-antenna can be simultaneously excited by thermal fluctuations, an essentially incoherent process arising from fluctuating thermal currents. Further, simulated electric field enhancement plots revealed that, due to the asymmetry of the MIM pair, the field can be localized at specific locations at different wavelengths.

The effect of hybrid modes on the resonant behavior of the currently considered antenna system may guide future efforts for realizing tunable optical and thermal systems for various applications, ranging from IR photodetection to multispectral biosensing. In particluar, through the combination of a small number of MIM antennas in a two dimensional array, it may be possible, through tailoring antenna dimensions and gaps, to produce a complex spectral response in the mid-IR and controlable field confinement.

\section{References}

[1] P. Bouchon, C. Koechlin, F. Pardo, R. Haïdar, and J-L. Pelouard. "Wideband omnidirectional infrared absorber with a patchwork of plasmonic nanoantennas." Optics letters 37, no. 6 (2012): 1038-1040.

[2] Y. De Wilde, F. Formanek, R. Carminati, B. Gralak, P-A. Lemoine, K. Joulain, J-P. Mulet, Y. Chen, and J-J. Greffet. "Thermal radiation scanning tunnelling microscopy." Nature 444, no. 7120 (2006): 740-743.

[3] C. Li, V. Krachmalnicoff, P. Bouchon, J. Jaeck, N. Bardou, R. Haidar, Y. De Wilde, "Nearfield and far-field thermal emission of an individual patch nanoantenna," Phys. Rev. Lett., 121, 243901 (2018).

[4] L. Abou-Hamdan, C. Li, R. Haidar, V. Krachmalnicoff, P. Bouchon, Y. De Wilde, "Hybrid modes in a single thermally excited asymmetric dimer antenna," Opt. Lett., in press (2021). DOI: 10.1364/OL.413382

[5] P. Nordlander, C. Oubre, E. Prodan, K. Li, M. Stockman, "Plasmon hybridization in nanoparticle dimers, "Nano Letters 4 , 899 (2004). 